pressed to detect transient pulsars at the low flux levels found with the Ginga scans of the galactic plane. There are a number of focusing X-ray telescopes slated for launch in the 1990s including the West German-US-UK satellite ROSAT, the

1. Koyama, K. et al. Nature 343, 148-149 (1990).

2. Special Issue for Ginga Pub. astr. Soc. Jap. 41, 345-426 (1989).

3. Maraschi, L., Treves, A. \& van den Heuvel, E. P. J. Nature 259, 292 (1976)

4. Nagase, F. Pub. astr. Soc. Jap. 41, 1-79 (1989)

5. Hayakawa, S., Ito, K., Matsumoto, T. \& Uyama, K. Astr Astrophys. 58, 325-330 (1977).

6. Trinchieri, G. in The Origin and Evolution of Neutron Stars (eds Helfand, D.J. \& Huang, J.H.) 149-159 (Reidel, Dordrecht, 1987)

7. Rappaport, S. \& van den Heuvel, E.P.J. in Be Stars, IAU Symp. 98 (eds Jaschek, M. \& Groth, H.) 327-344 (Reidel. Dordrecht, 1982)

8. Turner, M.J.L. et al. Pub. astr. Soc. Jap. 41, 347 (1989).

MOLECULAR GENETICS

\section{Mice, men and sickle cells}

\section{D.J. Weatherall}

WHEN trying to press the virtues of molecular medicine to sceptical clinicians or granting bodies, the story of sickle cell anaemia usually comes low on the agenda. For although the molecular basis of this often distressing condition was established by Vernan Ingram over 30 years ago, we still can do little more for our patients than could William Herrick when he first identified the disorder in a West Indian student in Chicago in 1910. One of the main constraints on research on this complex, multisystem disease has been lack of a good animal model. So workers in the field will be excited to read the title of the paper by David Greaves and his colleagues on page 183 of this issue of Nature ${ }^{1}$, which states that we now have a mouse model of sickle cell anaemia.

The facts of the disease are deceptively simple. Defective haemoglobin (S) differs from normal haemoglobin (A) by the substitution of valine for glutamic acid at position 6 in the $\beta$-globin chain ${ }^{2}$. In concentrated haemoglobin solutions that are partially or fully deoxygenated this change leads to polymerization of haemoglobin molecules and the formation of intracellular fibres which cause the sickle cell deformity. The deformity results in reduced flexibility of the red cell and hence in its impaired passage through the microcirculation ${ }^{3}$. This rheological abnormality has two results. First, red cells do not survive as long as they do normally, resulting in chronic haemolytic anaemia. Second -- and more importantly - small blood vessels become blocked by aggregates of sickled erythrocytes, leading to tissue damage.

If this were all, sickle cell anaemia would be a relatively mild disorder; the chronic anaemia is tolerated quite well and tissue damage may be minimal. But
Japanese satellite ASTRO-D, the US AXAF and European XMM missions which will have the sensitivity to detect these objects. But because these have relatively narrow fields of view, they cannot efficiently scan the galactic plane searching for new transients. Now that we know that transient $\mathrm{X}$-ray pulsars may be concentrated in small star-forming regions, however, these telescopes could monitor these parts of the sky and help to determine the duty cycles and absolute number of these enigmatic objects.

Charles Bailyn and Michael Garcia are at the Harvard-Smithsonian Center for Astrophysics, 60 Garden Street, Cambridge, Massachusetts 02138, USA. human $\beta$-globin locus and which direct high-level, copy-number-dependent expression of the human $\beta$-globin gene in erythroid cells in transgenic mice ${ }^{5}$. By inserting a construct which included two human $\alpha$ genes and the defective human $\beta^{\text {s}}$-globin gene, all driven by the DCR, it was possible to produce two mice that have relatively high levels of human haemoglobin $\mathrm{S}$ in their red cells. In vitro, these cells showed typical sickling in conditions of reduced oxygen tension; and the mice appear to have occasional irreversibly sickled cells in their circulation, showing that there may be some intravascular sickling in vivo.

These observations confirm that it is possible to obtain high levels of expression of human globin genes in mouse erythrocytes using the $\beta$-globin $\mathrm{DCR}^{5}$. But although the results are of considerable interest, a great deal more work is needed to find out how closely the mouse model resembles human sickle cell anaemia. In the two mice that have relatively large amounts of sickle cell haemoglobin in their red cells, the haematological findings at 4 and 15 days are indistinguishable from those of normal animals. In particular the transgenic mice are not anaemic and the reticulocyte count, a relatively sensitive indicator of red-cell turnover, is not elevated, indicating that their red cells are surviving as normal. It may be necessary to breed mice with higher levels of haemoglobin $\mathrm{S}$ in their red cells and to determine whether this leads to anaemia, tissue damage and the other protean manifestations of human sickle cell anaemia. It may turn out, of course, that the size of the red cells, the circulation dynamics and the regulation of the microcirculation are so different in mice and men that this will not be the case. Even so, it may still be possible to use the mouse model for testing anti-sickling agents.

Those trying to understand the pathology of sickling disorders will wait for the results of more prolonged observation of these transgenic animals with great interest. But it is far too early to say whether we have an animal model of sickle cell anaemia. This research field has had more than its fair share of false leads and disappointments - it is to be hoped that this will not be yet another. with little disability. Although a few genetic modifiers of the sickle cell phenotype have been identified ${ }^{3,4}$, the reasons for such clinical heterogeneity are not understood. This is of particular relevance now that the disease can be identified early in fetal life; counselling parents at risk for having children with the condition is particularly difficult.

The apparent tour de force reported by Greaves et al. ${ }^{1}$ resulted from the recent identification of the dominant control region (DCR) sequences which flank the

D.J. Weatherall is in the Institute of Molecular Medicine, University of Oxford, John Radcliffe Hospital, Headington, Oxford OX3 9DU, UK.

\footnotetext{
Greaves, D.R. et al. Nature 343, 183 - 185 (1990).

Ingram, V.M. Nature 178, 792 (1956)

Schechter, A.N., Noguchi, C.T. \& Rodgers, G.P. in The Schechter, A.N., Noguchi, C.T. \& Rodsers, G.P. in 7 179 - 218 (Saunders, Philadelphia, 1987)

4. Serjeant, G.R. Sickle Cell Anaemia (Oxford University Press, 1985)

5. Grosveld, F., Blom van Assendelft, G., Greaves, D.R. \&
} Kollias, G. Cell 51, 975 - 985 (1987) 